\title{
How do School Management Teams Experience Teamwork: A Case Study in the Schools in the Kamwenge District, Uganda
}

\author{
Victor J. Pitsoe \\ Department of Leadership and Management, \\ College of Education, University of South Africa \\ E-mail address: Pitsovj@unisa.ac.za \\ Peter Isingoma \\ Link Community Development, Kamwenge District, \\ P.O.Box 25630 Kampala, Uganda \\ E-mail address: isingomapeter@yahoo.com
}

Doi:10.5901/mjss.2014.v5n3p138

\begin{abstract}
Teamwork is an essential tool to achieve success for any organisation. In the absence of teamwork, teams fail to perform to the best of their abilities. This study was conducted on a purposeful sample of 40 teachers from ten government grant-aided primary schools, working in cooperation with Link Community Development, a non-governmental organisation. A survey questionnaire and interviews were used to collect data from the ten primary schools in the Kamwenge District. In this paper, we will take a look at the perceptions about and knowledge of teamwork among head teachers and teachers; the skills and competencies required for effective teamwork; the benefits of teamwork and its impact on teaching and learning; the challenges related to teamwork; and, finally, guidelines that can be employed by the School Management Teams (SMTs). The study revealed that teamwork among SMT members impacts positively on the quality of teaching and learning.
\end{abstract}

Keywords: teamwork, school leadership, team performance, motivation, benefits of teamwork.

"Coming together is a beginning. Keeping together is progress. Working together is success." Henry Ford

\section{Introduction}

The citation above captures the importance given to teamwork in today's changed work environment. Teamwork is an important component of effective and efficient leadership. It refers to a process where work is performed by a team to achieve a common goal. Within the context of the school environment, teamwork plays a key role in the effort to improve outcomes as it influences the level of motivation and capacity of teachers, as well as the school climate and environment. Research suggests that teamwork can be likened to two kinds of substances that play an important role in modern life. Firstly, it is the glue that keeps the team together and a bond that promotes strength, unity, reliability and support. Secondly, teamwork is the lubricant that makes the team work. It enables smoother movement towards targets, assists forward momentum, and it helps teams to overcome obstacles. Hence, learning about the importance of teamwork is one of the stepping stones one needs to be successful in both your career and personal life.

In many schools, teachers work in isolation, school principals try to accomplish tasks alone, and the responsibility for implementing new ideas falls on the individual. However, working together in a team is often a more effective way to accomplish important tasks. Thus, teamwork is central in the efficient and effective management of schools - it is a vital force in improving schools. Apart from the challenges associated with the implementation of the Universal Primary Education (UPE) in Uganda, the absence of teamwork, among others, at schools in the Kamwenge District appears to have impacted on teachers' performance in the classroom; and on the quality of teaching and learning. With this in mind, we argue that the absence of teamwork, deemed essential in today's changing work environment (in schools), could potentially affect the Universal Primary Education policy. Little research, if any, has been conducted on teamwork at the schools in the Kamwenge District. Against this backdrop, the purpose of this study was to investigate the perceptions about, knowledge of and competencies required for teamwork among head teachers, deputy principals, female senior teachers and head of subjects - who all form part of the school management team (SMT) - at the schools in the 
Kamwenge District, Uganda. In this article we begin by capturing literature on teamwork in the schooling context. This is followed by a research methodology; then the findings and discussions; and, finally, the recommendations and conclusion are provided.

\section{The Literature on Teamwork}

Teamwork has become a critical skill in the twenty-first century. Globally, competitive markets' real success lies in the performance of its team. However, teamwork has a very rich history. It is not practised only in the business world today, but is one of the oldest things known to man. Interestingly, mankind has worked in teams and groups since the primitive days of civilisation. The traces of teamwork are visible almost everywhere. According to Dyer (2008), the idea of working in a team can be traced back to the late 1920s and early 1930s with the now classic Hawthorne studies. Grayson (2012), on the other hand, states that the earliest formal studies of teamwork took place after World War II and focused on discovering the reasons for the failure of military teams. Grayson (2012) notes that the first scholarly study of teamwork took place in the 1950s under the direction of psychologists who examined how humans relate to themselves and others. This group also looked at how work influences team interactions and the actions team members take to tap into the talents and skills of other members in order to solve a task or problem at work. Other studies explored the changes that occurred in teams over time and how teams have integrated technology in the completion of tasks.

There are numerous definitions of teamwork. The concept "team" has been widely used in different social sciences including anthropology, sociology, psychology, etc.; hence, it has different definitions based on the field of study. Most scholars (Cardona \& Wilkinson 2006; Grayson, 2012; Greenwood, 2012; Phalane, 2012; Medwell, 2009) see a team as a group of individuals who come together to work cooperatively on a task in order to achieve a common goal, while teamwork refers to the activities of a group of individuals, which can include effective communication and interaction among the team members to promote knowledge sharing, understanding of each other on a personal level, helping others in achieving a level of perfection, building a sense of unity in the team and working towards the achievement of common goals. As Medwell (2009:320) observes, teamwork is when individual experts gather as a workgroup and set goals, communicate, cooperate and make decisions together, combining their knowledge and abilities to compile work plans that will enable them to accomplish their goals. With this background in mind, schools today are largely concerned about learning and are taking every possible step to increase students' performance. One approach that has had a very substantial and positive impact on school performance is teamwork. Effective teamwork is a very important methodology which schools can use to develop teachers' potential to the fullest. In the context of the school environment there is a theoretical and practical divide. Head teachers seem to know the theory of teamwork, but have failed to put it into practice. The fact is that teamwork as a method has been used so languidly over the years that in some cases, it has ceased to be what it stands for and, instead, it has rather become a cliché.

Teamwork is an indispensable element in the success and profitability of organisation. Among others, working in a team has the advantage that the workload can be distributed among all the team members. In addition, working as a team can benefit the individual, the team and the organisation. Recent research (Phalane, 2012) findings reveal that in the school environment improvement and effectiveness can be realised through teamwork. With most continuing professional development programmes for teachers, teamwork skills seem to receive little formal attention. Acquiring these skills is critically important, especially for head teachers as they advance and assume supervisory responsibilities for the school management teams (SMTs). Teamwork is a tool that can be used to improve the quality of teaching and learning. This is demonstrated, for example, in team teaching, for example, which facilitates more interaction between teachers and that may result in an improved quality of teaching and learning. With teamwork teachers' strengths are combined and their weaknesses are remedied, while underperforming teachers can be observed, critiqued and advised about how to improve by other team members in a non-threatening, supportive context.

Cardona and Wilkinson (2006:34) argue that each team member has his or her own personality and brings to the task particular skills, knowledge and experience, which are different from those of other team members. According to them teamwork reduces teacher isolation, increases collegiality, facilitates the sharing of resources and ideas, and capitalises on teachers' individual and shared strengths. It also enables schools to achieve their goals within a predetermined timeframe by using their knowledge of administration and uniting the physical power, will power and intellectual power of participants to be the same in teamwork (Catharine 2009:45).

Teamwork and school leadership have a symbiotic relationship. Schools, as organisations, require leaders to motivate, direct and drive teachers as well as administrative personnel in order to move the schools forward. Strong team leadership that motivate, develop and guide teachers and administrative personnel can result in lower costs for the 
organisation (Oster 2012). A high level of job satisfaction among teachers and administrative personnel leads to lower employee turnover and higher productivity. Hence, teamwork plays an important part in successful organisational operations. Productive teams help build businesses and create effective organisations. Greenwood (2012) contends that teamwork can compel people to expand their skills and to learn from one another in ways that might never have occurred had they not been placed on the same team. In addition, it can encourage members to learn to respect and appreciate each other as well as promote a sense of belonging.

According to Oster (2012), teamwork has become an essential element in the success and survival of a business. He maintains that teams are able to reach their goals when they have inspiring leaders, well-qualified team members and well-defined goals or missions. Research (Phalane 2012; Greenwood 2012) shows that team members should have the following attributes: (1) a common purpose and clear goals; (2). the necessary skills and resource; (3) a common approach to work; (4) the willingness to share information; (5) trust and support in each other; (6) the ability to work through conflict; and (7) the willingness to take responsibility for team actions.

\section{Methodology}

Based on a survey research design, the study was conducted on a sample of 40 teachers from ten government grantaided primary schools, working in cooperation with Link Community Development, a non-governmental organisation (NGO). Link Community Development is geared to improve teaching, learning and governance in primary schools. The participants were teaching at mixed-gender, day schools; six schools were located in the rural areas, one in a peri-urban area and three in urban areas covering different sub-counties in the Kamwenge District. The participants' views were assumed representative of the current state of affairs in the district. The data for the survey was generated from ten head teachers, ten deputy head teachers, ten female senior teachers and ten head of subjects in the ten sampled primary schools. The sample included four participants from each of the ten schools, because these participants are part of the school management team (SMT). According to McMillan and Schumacher (2001:175), purposeful samples are sometimes called "judgmental sampling" because the researcher selects particular elements from the population that will be representative or informative about the topic of interest. A survey questionnaire and interviews were used to collect data from the ten primary schools in the Kamwenge District. The survey used a mixed method approach which includes both quantitative and qualitative methods. Semi-structured interviews were conducted and data were collected through a questionnaire which had closed-ended and open-ended questions to the 40 members of the SMTs.

The participants had teaching experience ranging from 7 to 30 years. They had the following academic qualifications: Grade III Teacher's Certificate (30\%), Grade V Diploma in Primary Education (50\%) and graduate teachers (20\%). The Grade III Teacher's Certificate is awarded to students who began teacher training after having completed Senior Four or Ordinary Level and is the lowest qualification. Those teachers who have the Grade V Diploma in Primary Education are teachers who, after three years of teaching, upgraded from Grade III. The data was analysed through gathering descriptive statistics and information regarding the current perceptions about, knowledge of and competencies in teamwork of school head teachers, deputy head teachers, female senior teachers and heads of subjects at the schools in the Kamwenge District, Uganda.

\section{Findings and discussions}

The findings of the study are presented in regard to the investigation on how SMT members experienced teamwork at the schools, their perceptions of teamwork, whether they have sufficient knowledge of and skills in teamwork, the impact teamwork has had on the quality of teaching and learning in their respective schools and the guidelines SMTs can employ to build on teamwork in schools.

\subsection{How the head teachers in the ten schools perceive teamwork}

During the interviews, it became apparent that teamwork was not a new concept in the schools; the head teachers and the other SMT members were familiar with this method. The head teachers described teamwork as follows: 


\begin{tabular}{|c|c|}
\hline School & Description of team work \\
\hline One & $\begin{array}{l}\text { Teamwork is a unit or [the] total output of activities in a school to achieve its missions and } \\
\text { objectives. }\end{array}$ \\
\hline Two & $\begin{array}{l}\text { In teamwork members of staff can learn from each other more easily and completing a task } \\
\text { becomes easy. }\end{array}$ \\
\hline Three & $\begin{array}{l}\text { Teamwork is [being thankful for] the effort put in by each person in the school and not [playing the } \\
\text { blame game] during the implementation of planned activities. }\end{array}$ \\
\hline Four & $\begin{array}{l}\text { In teamwork teachers are given flexibility in carrying out school tasks together - this is arrived at } \\
\text { after a staff meeting and greatly promotes targeted activities of the school that improve the teaching } \\
\text { and learning process. }\end{array}$ \\
\hline Five & $\begin{array}{l}\text { Teamwork is when staff members share information and get involved in discussions [about matters } \\
\text { that affect] school performance, and listen to the contributions of all members. }\end{array}$ \\
\hline Six & $\begin{array}{l}\text { Teamwork is when all the staff members' different talents and experience are put together in a } \\
\text { coordinated manner to maximise the performance of the learners in the school. }\end{array}$ \\
\hline Seven & $\begin{array}{l}\text { Teamwork [is] a way of giving staff members a chance to learn, gain experience and grow } \\
\text { professionally by taking on different and coordinated tasks and roles so that, at the end of the } \\
\text { process, most staff members have been mentored. }\end{array}$ \\
\hline Eight & With teamwork solutions to the different problems at school can be found at minimum cost \\
\hline Nine & $\begin{array}{l}\text { Teamwork increases the chances of staff membersto participate in decision making, especially } \\
\text { when the views and suggestions of members are brought together in activities such as staff } \\
\text { meetings }\end{array}$ \\
\hline Ten & $\begin{array}{l}\text { Teamwork makes [members] share school responsibilities and roles, and makes each member } \\
\text { know what is going on in the school }\end{array}$ \\
\hline
\end{tabular}

What is clear in the descriptions is that teamwork increases efficiency in the schools' quality output. With teamwork more activities can be carried out using the available resources because it increases the motivation of staff and ensures that the correct professional decisions are taken.

The concept "united we stand and divided we fall", is a widely known concept. This concept also applies in the case of a team in a school. Collective team activities are very important if the school or a process wants to reach its goal. There are some tasks that cannot be done individually, but it can be easily accomplished when working together as a team. Sundstrom et al. (1990) indicate that working teams have been regarded as a structural form that is essential in achieving business objectives in organisations. Hence, schools, which are also organisations, qualify to be managed and led using the teamwork approach. Teamwork plays a major role in organisations; it increases work performance and result in better outcomes. There is wisdom and much to learn from ants and their colonies in terms of the benefits of teamwork and fostering a team spirit. Ants survive through teamwork, they are highly skilful, highly social and highly intelligent.

\subsection{Benefits of teamwork}

Teamwork is increasingly gaining popularity in schools, is essential for improving schools and plays a key role in achieving better school outcomes. The reason for this is that teamwork has an impact on the motivation levels and capabilities of teachers as well as the school climate and environment. The majority of the SMT members interviewed in this study agree that teamwork is likely to produce good results and can maximize learners' achievements in their schools. Figure 1 shows that all the SMTs agree and strongly agree that teamwork benefits the schools.

Figure 1: Teachers' agreement regarding the benefits of teamwork

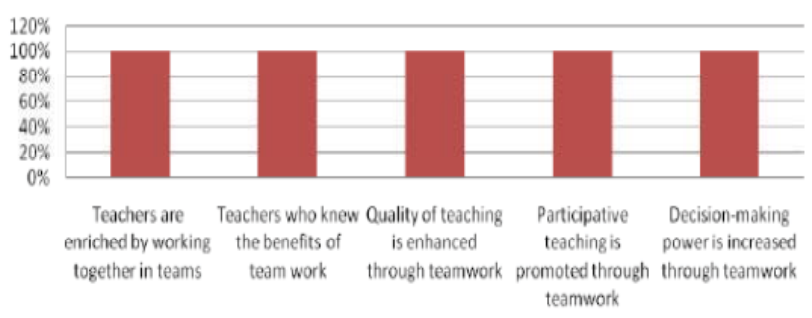


The respondents believe that working in teams will enrich them professionally; it will enhance the quality of teaching; promote participative teaching and increase the power of decision-making. It was evident from the SMTs interviewed that a small reward given to teachers with unique skills and strengths could help to encourage a bigger effort for the benefit of the school.

\subsection{Knowledge and skills on teamwork}

Members of the SMT conceded that knowledge and skills are needed so that teamwork is effectively applied in schools. However, a number of the members of the SMTs have had minimal or no training in teamwork as shown in Figure 2.

Figure 2: Number of trainings held by SMTs

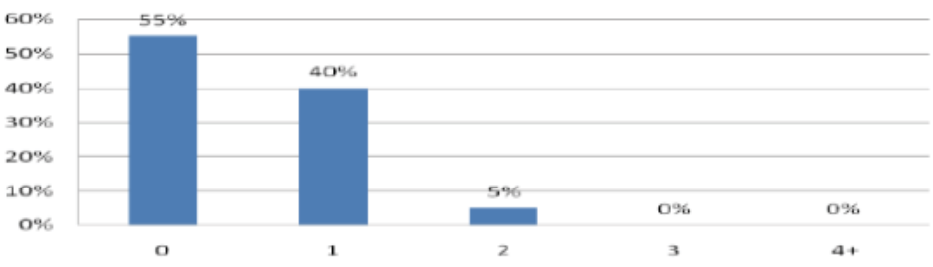

In the interview, it became apparent that the SMTs use the experience and expertise of their members to organise or lead some activities. One SMT member explained;

"When we identify that one member of staff has knowledge and skills in one area, the staff will ask him/her to demonstrate/train and mentor them in the identified weak area and he/she coordinates to ensure that there is improvement."

What also turned out to be an outstanding tool to enhance teamwork in schools was having regular meetings, where teachers were updated on the school activities. One deputy head teacher clarified:

"During the regular guided staff meetings held at school, short consultation is done by the head teacher and in that process we, the staff members, see transparency in the implementation of school activities and we are happy to observe that our input become part of the school's resolutions and this renders staff members free to consult with each other."

During these meetings teachers' fears are addressed. What the study revealed is that knowledge of and skills in managing teamwork are needed to enhance teamwork in schools and, therefore, workshops/training should be given a priority.

Figure 4: Competence levels in teamwork

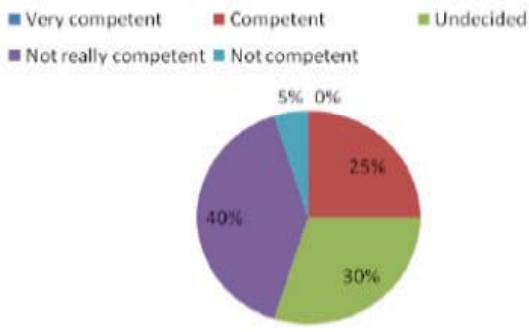

The study revealed that only $25 \%$ of the SMT members were competent, $30 \%$ were undecided, $40 \%$ were not really competent and $5 \%$ were not competent. It is evident that knowledge and skills are needed to implement teamwork. 


\subsection{Impact of teamwork on quality of teaching and learning}

Teamwork, as seen in team teaching, facilitates more interaction among teachers and this may result in an improved quality of teaching and learning. Teachers' strengths are combined and weaknesses are dealt with. Underperforming teachers can be observed, critiqued and suggestions for improvement can be made by other team members in a nonthreatening, supportive context. Therefore, teamwork plays a major role in organisations and increases work performance and result in better outcomes, while the absence of teamwork in schools impacts on the quality of teaching and learning. Some of the views expressed by the SMT are as follows:

\footnotetext{
"Common tasks are tackled together and planning for assessment of learners is done collectively as a team to enhance the quality of teaching and learning."

"When there is teamwork I, as a deputy head teacher, find it easy to supervise teachers' schemes of work and lesson plans without suspicion or fear from (sic) them."

"The teachers' areas for improvement can easily be identified and strategies to address them can be planned at school level."

"Teachers' varied skills and experience are put together to enhance teaching and learning and teachers who are weak improve in the process of working together (sic)."

"Friendship, morale and positive learning is developed in teamwork when teachers share insights, methods of teaching with each other."

"Where classes are large, the teachers with their different personalities bring about varied approaches that give variety of activities (sic) in the classroom to enhance learning."
}

Wilkinson (2008:45) concludes that when teachers see that there is an improvement in the quality of teaching and learning, their self-esteem improves and happiness increases and this, in turn, aids in the recruitment and retention of educators in the system.

\subsection{What guidelines can be employed by the SMTs to build on teamwork in schools?}

The basic tenet for promoting teamwork in a school setting is that there has to be increased interaction among the teachers or team members. This helps them to understand each other and deal with the different aspects of their behaviour, both negative and positive within the context of the school tasks. Here are some of the ways in which effective teamwork can be promoted in the school (Deshmukh, 2011). There has to be a clear understanding of what teamwork is and that there is no place for "ME"' or "I" in the school. This attitude will only hamper the idea of the "team". Teamwork becomes easier to promote when there is an efficient leader in place to guide the team:

- It is important that the team members feel important in the school. They have to be encouraged to provide their inputs and any other suggestions. When team members know that they are an important part of the organization and that their contributions are valued, they will be more willing to work.

- It is very important to have clear goals in place and an understanding of how to achieve them well enough. This needs to be discussed in the meetings. Most schools arrange for monthly or bi-monthly meetings for their staff whereby they provide a platform to discuss their problems and find solutions for the same. This leads to clearing of any conflicts, problems and lends for a better understanding of the goals and how to get there.

The respondents generally appreciated the support they were getting from the team members and this increased their morale and the team members became more committed to what they were doing. A few recorded responses are as follows:

"When I do some assignment together, with assurance of support from the administration or parents, I do it with vigour because I know that my work will be recognised."

"There is need of encouragement, support and give direction in all what we are doing as teachers, we feel as part of the school (sic) when all is done well and this makes us happy and willing to continue."

"As a head teacher my big task is to give maximum support to my staff by showing him/her what to do, give him/her what material is needed which is available, and build in him/her the spirit of working together in order complete the task at hand successfully." 


\subsection{Challenges of teamwork}

All the SMTs accepted that teamwork is important for schools as it will help them to achieve their objectives, but they also recognised that it brings with it certain challenges. The SMTs responses highlighted these challenges as follows:

"To organise teamwork, one has to call a meeting, some teachers don't enjoy staying in meetings taking long time [sic]. Such meetings can jeopardise teamwork."

"When some teachers are sluggish and lazy it can be difficult and challenging to have some assignment done effectively in teamwork arrangement in time [sic]."

"Loyalty is one issue that all members in the team should maintain. If all agree on some principles, all members should adhere to it, but if one or some members fail to comply with what was agreed by the team, then some disagreement will come up [sic]."

"Many teachers are not the same in ideas [sic] so teamwork may not work well in such schools that have many teachers with divergent ideas and opinions."

"If a task needs urgent attention, a head teacher may consult only one member of staff or decide to do the task alone resulting in failure of teamwork."

"If some members in the team are slow and others are quick you will find that some members in the team are left to do more of the team's task than others."

"Some head teachers think that no members on the staff can do particular assignment to their expectations, it's even difficult to find a head teacher with such opinion delegating to his members of staff. This type of head teacher cannot make good teamwork [sic]."

"In teamwork all have to share and do activities as per the approved schedules, but if you find that some members want to do things alone or by themselves, even after reaching an agreement on who should do what, then distrust will come up and this will hinder teamwork succeed [sic]."

The study reveals that the SMTs sometimes, depending on the nature of the task and the available skills of the staff members, do not opt for teamwork when they want to accomplish the task. They sometimes use their discretion while in the process of executing their duties.

\section{Recommendations}

In the light of these findings, we recommend that:

- the district education office give more support be given to the SMTs in form of necessary training to enhance teamwork in schools;

- induction programmes be conducted in all schools to impart skills and knowledge to SMTs to empower them and improve teamwork;

- the district inspectorate mentor the SMTs on teamwork skills during their school monitoring visits;

- the SMTs, in their respective schools, make use of teamwork to achieve the schools' objectives;

- the head teachers encourage teamwork in the schools by tapping into the potential of all members; and

- senior members of staff mentor junior members through delegation of tasks.

\section{Conclusion}

The purpose of this paper was to investigate SMTs' the perceptions about, knowledge of and competencies in teamwork at the schools in the Kamwenge District, Uganda. The study reveals that the concept of using teamwork is accepted by all members of the SMTs and that it recognises the many advantages of this method. The responses of the participants showed that SMT members perceive teamwork positively and they confirmed that teamwork plays a major role in schools and that it increases work performance and resulted in better outcomes. It furthermore creates an environment where there is shared responsibility, opportunities for knowledge sharing and continuous professional and personal 
development of the members. It is clear from the study that some of the SMT members still lack the knowledge and skills needed to implement team work in schools. It became apparent that this was a big deterrent to the execution of teamwork.

The study revealed that teamwork among SMT members impact positively on the quality of teaching and learning. When teachers work together, develop trust among each other, and when there is support the quality of teaching and learning in the whole school improves, but where there is no teamwork, improvement in the quality of teaching and learning is not realised. SMT members should work together, as one unit, to pursue the overall school goals. It would be interesting to examine these identified factors. The implications of the attributes of teamwork, the problems and challenges identified in this study call for further research. More focused education policies, and more support for teachers to improve teamwork, will help to shape the future of education in Uganda.

\section{References}

Cardona, P \& Wilkinson, H. (2006). Teamwork. Abstract: IESE Business School. University of Navarra.

Catharine, J. (2009). Using collaborative action teams to create community schools. National Association of secondary school Principals. NASSP Bull. 83(611): 48-56.

Deshmukh, I. (2011). How to promote teamwork in workplace. From http://www.buzzle.com/articles/how-to-promote-teamwork-inworkplace.html Date Accessed 10 October 2012.

Dyer, J.L. (2008). Team research and team training: a state of the art review. Human factors Review, 5: 285-319.

Grayson, L. (2012). Theories on Teamwork. http://work.chron.com/theories-teamwork-6545.html (Accessed 10 October 2012).

Greenwood, B. (2012). Benefits of collaboration and teamwork. http://work.chron.com/benefits-collaboration-teamwork-3618.html (Accessed 10 October 2012).

MacMillan, J.H. \& Schumacher, S. (2001). Research in education, a conceptual introduction. New York: Longman.

Medwell, J. (2009). Developing a model of teacher-team building at secondary schools in Thailand. New York: Longman.

Oster, K.V. (2012). Teamwork explained. http://work.chron.com/teamwork-explained-8261.html (Accessed 10 October 2012).

Phalane, M.M. (2012). Experiences of secondary school management teams on teamwork in Tshwane North District schools. Published MEd dissertation, University of South Africa, South Africa.

Sundstrom, E., Demeuse, K.P. \& Futrell, D. (1990). Work teams: applications and effectiveness. American Psychologist, 45(2): $120-33$. 